\title{
História da Educação Matemática na Revista do Ensino de Minas Gerais (1925-1971)
}

History of Mathematics Education in Revista do Ensino de Minas Gerais (1925-1971)

\author{
Flávia Aparecida Britto ${ }^{1}$ \\ Maria Laura Magalhães Gomes ${ }^{2}$
}

\begin{abstract}
Resumo
Neste artigo, discutimos aspectos teórico-metodológicos do uso de periódicos educacionais como fonte de pesquisa e focalizamos uma investigação sobre a matemática e o seu ensino na Revista do Ensino de Minas Gerais (RE) - impresso oficial de extrema importância para a história da educação mineira que circulou de 1925 a 1971. Tal investigação tem como corpus textos publicados na RE até 1940 que contêm referências à matemática ou a seu ensino. Ao levantarmos as características gerais desse corpus, constatamos que é variado o grupo formado por seus autores e coautores, que inclui personalidades do cenário político-pedagógico da época. Notamos, ainda, que o tipo mais frequente de texto é o relato de experiência/ observação/ pesquisa/ estudo e que foi muito expressiva na RE a presença dos seguintes temas: a matemática nas escolas após as reformas de 1927; concepções/ visões/ valores relacionados à matemática e/ou a seu ensino; orientações/sugestões para a abordagem de conteúdos matemáticos.
\end{abstract}

Palavras-chave: História da Educação Matemática, Periódicos Educacionais, Revista do Ensino de Minas Gerais.

\begin{abstract}
This article discusses theoretical and methodological aspects of the use of educational journals as a source of research and focuses an investigation on mathematics and its teaching in Revista do Ensino de Minas Gerais (RE). This journal circulated from 1925 to 1971 and is a very important source for research on history of education in Minas Gerais. The investigation aims at every text published RE until 1940 containing references to mathematics or its teaching. When we raise the general characteristics of such texts, we find that the group formed by its authors and co-authors is varied and includes personalities from the political-pedagogical scenario of the time. We also note that the most frequent type of text is the report of experience / observation / research / study and that the presence of some subjects as mathematics in schools after the reforms of 1927, conceptions / visions / values related to mathematics and / or their teaching, guidelines / suggestions for the approach of mathematical contents is very significant.
\end{abstract}

Keywords: History of Mathematics Education, Educational Journals, Revista do Ensino de Minas Gerais.

Submetido em: 19/10/2018 - Aceito em: 29/03/2019 - Publicado em: 30/03/2019

${ }^{1}$ Doutoranda em Educação do Programa de Pós-Graduação em Educação da Universidade Federal de Minas Gerais. Professora do Centro Universitário de Belo Horizonte - UniBH. Email: flaviaapbritto@gmail.com.

2 Doutora em Educação pela Universidade Estadual de Campinas. Bolsista de Produtividade do CNPq. Professora do Departamento de Matemática e do Programa de Pós-Graduação em Educação da Universidade Federal de Minas Gerais, Brasil. Email: mlauramgomes@gmail.com. 


\section{Introdução}

DOI: https://doi.org/10.20396/zet.v27i0.8653725

As alterações na prática historiográfica ocorridas nas décadas finais do século $\mathrm{XX}$, implicaram uma ampliação do campo e das temáticas de estudo dos historiadores (Toledo; Skalinski Junior, 2012). Nesse movimento, novas fontes passaram a ser legitimadas, dentre elas a imprensa periódica. Em se tratando da História da Educação, tem crescido nos últimos anos a quantidade de estudos em que impressos pedagógicos são fonte de pesquisa e objeto de investigação.

Focalizamos, neste artigo, aspectos teórico-metodológicos e alguns resultados de um estudo sobre a presença da matemática no periódico oficial mais representativos da história da educação mineira - A Revista do Ensino de Minas Gerais (RE). A RE, criada em 1892, manteve publicações ao longo do período de 1925 a 1971, sofrendo uma interrupção de circulação de 1941 a 1945 devido à Segunda Guerra Mundial. Nossa pesquisa contempla a análise dos textos do impresso em que são encontradas referências à matemática ou a seu ensino veiculados na sua primeira fase de circulação - 1925 a 1940, a qual concentra a maior parte dos volumes publicados em seu ciclo de vida. Neste texto, porém, em alguns aspectos, abordamos o impresso em todo o período em que circulou.

\section{Os periódicos educacionais como fonte de investigação}

Ao fazer um retrospecto do aparecimento das revistas pedagógicas, Catani (1996) indica que foi a partir das últimas décadas do século XIX que os periódicos educacionais começaram a ser editados no Brasil. Dentre os pioneiros, estão a Revista do Ensino do Rio de Janeiro (1883), a Revista do Ensino de Minas Gerais (1892) $)^{3}$ e a revista A Escola Pública (São Paulo, 1893) ${ }^{4}$. No entanto, a autora alerta que cada publicação apresentou uma marca local bastante acentuada, o que requer uma atenção específica aos diferentes estados do Brasil. As iniciativas de publicações periódicas educacionais de caráter nacional ocorreram apenas mais tarde, na década de $1940^{5}$.

\footnotetext{
${ }^{3}$ A denominação Revista do Ensino também foi usada como título de periódicos que circularam nos estados do Pará, Bahia, São Paulo e Rio Grande do Sul.

4 Catani (1996) indica que, após esses periódicos pioneiros, uma série de outros surgiram, aumentando consideravelmente o número de edições pedagógicas especializadas em educação. São citadas Educação $e$ Ensino: revista pedagógica da instrução pública municipal (Rio de Janeiro, 1897); A Escola: órgão da Associação dos Professores do Brasil (Rio de Janeiro, 1900); A Escola: publicação do Grêmio dos Professores Públicos do Estado do Paraná (Paraná, 1902); A Escola: revista oficial do ensino (Pará, 1902); Revista Didática: regenerar o ensino ensinando (RJ, 1903); Ensino primário (Pará, 1910); O Estudo: Publicação da Sociedade de Estudos Pedagógicos de Professores do Distrito Federal (Rio de Janeiro, 1908) e Revista do Ensino (Pará, 1911).
}

\footnotetext{
5 Segundo Catani (1996), uma exceção é a Revista Pedagógica (1890-1896) do museu pedagógico Pedagogium, fundado no Rio de Janeiro em 1890 e extinto em 1919.
} 
DOI: https://doi.org/10.20396/zet.v27i0.8653725

Anteriormente à existência desses impressos pedagógicos, já se notava, porém, alguma abordagem de assuntos educacionais em periódicos não especializados em educação, como é o caso da Revista Moderna, editada em São Paulo a partir de 1892.

Em relação ao tratamento de questões sobre o ensino e aprendizagem da matemática em periódicos, Brito e Miorim (2012) observaram a existência de referências à temática em publicações impressas desde o ano de 1820. Ao estudarem o periódico A Gazeta do Rio de Janeiro, o primeiro impresso no Brasil, colocado em circulação em 1808 pela recém-criada Imprensa Régia, Brito e Miorim (2012) localizaram, no exemplar do dia 08 de janeiro de 1820, um texto sobre os caracteres numéricos de diferentes povos. As autoras também perceberam outras referências à matemática ou ao seu processo de ensino e aprendizagem nos anos seguintes, tanto em periódicos não especializados em educação, como O Patriota, Jornal Litterario, Politico, Mercantil, \&c. do Rio de Janeiro, quanto em alguns especializados, a exemplo da Revista do Instituto Polytechnico Brasileiro.

Há indicativos de que, em alguns momentos, os impressos educacionais chegaram a se constituir como guias de referência para o fazer docente. Carvalho (2001, p.84), ao estudar o papel do impresso pedagógico na difusão do ideário escolanovista, observa, por exemplo, que, nesse contexto, os periódicos educacionais tinham um caráter de "ferramenta de trabalho" oferecida ao professor para transformação de suas práticas, "um roteiro e referência para a ação".

Vê-se, portanto, que a análise do conteúdo dos impressos pode trazer importantes informações para estudos no campo da História da Educação. Entende-se, atualmente, que a imprensa periódica educacional, envolvendo "jornais, boletins, revistas, magazines - feitas por professores para professores, feitas para alunos por seus pares ou professores, feitas pelo Estado ou outras instituições como sindicatos, partidos políticos, associações de classe, Igrejas" (Bastos, 2007, p.167), pode se constituir

como um farto material acerca das práticas escolares e do ensino específico de disciplinas, oferecendo assim possibilidades de se estabelecer um dos elos da história das práticas e das disciplinas escolares. Dessa forma, o estudo da imprensa periódica especializada em educação pode trazer elementos extremamente úteis para compreensão histórica do sistema de ensino e colocar novas questões acerca da "cultura escolar brasileira (Sousa \& Catani, 1994, p. 177).

Levando em consideração essas potencialidades, observa-se que o uso de jornais e revistas pedagógicas como fonte de pesquisa tem crescido consideravelmente nas últimas décadas no âmbito da História da Educação (Rios \& Fischer, 2016). Uma das explicações para o crescimento está, como comentamos, no reconhecimento recente de que esses impressos seriam uma fonte legítima. Luca (2005) relata que, até a década de 1970, ainda era relativamente pequeno o número de pesquisas que usavam jornais e revistas como fonte para o conhecimento histórico, especialmente porque a tradição historiográfica se pautava no ideal de busca da realidade dos fatos. Nesse contexto, preconizava-se o uso exclusivo de fontes "objetivas e neutras", qualidades não atribuídas aos periódicos, que eram concebidos como 
DOI: https://doi.org/10.20396/zet.v27i0.8653725

registros fragmentários, realizados sob o influxo de "interesses, compromissos e paixões" (p.112).

Faria Filho (1997) nos adverte, no entanto, que ainda que a História da Educação tenha sido enriquecida com a utilização das chamadas "novas" fontes, o uso delas em pesquisas "exige, ou tende a exigir, um trabalho do(a) pesquisador(a) no sentido de explicitar e explorar tanto suas especificidades quanto as possibilidades de cruzamento com outras modalidades de fontes" (p.111). Dessa maneira, torna-se necessário, segundo o autor, desenvolver uma teoria de cada um dos acervos documentais a serem investigados, bem como questionar e entender suas particularidades, materialidades e relações com o seu "lugar" de produção.

De modo particular, no que diz respeito ao uso dos periódicos, Farias (2014) entende que, ao se pesquisar jornais e revistas, "descompactamos linguagens e criamos uma nova narrativa". Segundo a autora, para elaborarmos uma narrativa usando essas fontes, "compactamos as linguagens novamente de um outro lugar e de um outro tempo para novas releituras" (p.10). Tais procedimentos demandam um tratamento metodológico cuidadoso do pesquisador.

Considerando as particularidades e precauções necessárias, diversos estudos têm proposto reflexões e explicitado indicações de cunho teórico-metodológico sobre a adoção de periódicos como fonte de investigação.

Cruz \& Peixoto (2007) consideram que a imprensa é uma força ativa da história e não uma mera depositária de acontecimentos, assim como é uma "linguagem constitutiva do social", que fala de um certo lugar em um determinado tempo e, por isso mesmo, precisa ser posta em constante diálogo com a sociedade e com os movimentos de constituição e instituição social que a geraram. De modo análogo, Fernandes \& Kuhlmann Júnior (2012) entendem que é preciso tanto situar o impresso no interior da história social, buscando articulações com a história mais ampla, como também compreender seu projeto gráfico e editorial e as suas condições de produção, circulação e significação.

Búrigo (2016), pesquisadora da história da educação matemática, destaca a importância de serem tomados três cuidados no trabalho com a fonte periódica. O primeiro é a crítica aos documentos, por meio da interrogação sobre as condições e intenções envolvidas na sua produção e do conhecimento dos destinatários, das motivações para a sua guarda, arquivamento ou esquecimento. $\mathrm{O}$ segundo cuidado corresponde à análise não apenas dos textos e imagens, mas também do suporte material, que, segundo ela, interfere na produção de sentido pelo leitor. $O$ terceiro cuidado refere-se à importância do cruzamento de fontes, isto é, os periódicos precisam ser usados e analisados em diálogo com outros documentos.

Chartier (1990) também pontua que "não existe nenhum texto fora do suporte que o dá a ler" (p.127). Assim, podemos perceber que diversos elementos e atores são colocados em relação quando se produz e faz circular um periódico. Darnton (2010), ao pensar no ciclo de vida de um livro, desenvolveu uma representação esquemática (Figura 1) chamada "O circuito das comunicações", que nos possibilita uma visão dos elementos e atores envolvidos 
DOI: https://doi.org/10.20396/zet.v27i0.8653725

na produção e circulação de um impresso, a qual consideramos que também se aplica, de modo geral, ao processo de edição e circulação de jornais e revistas.

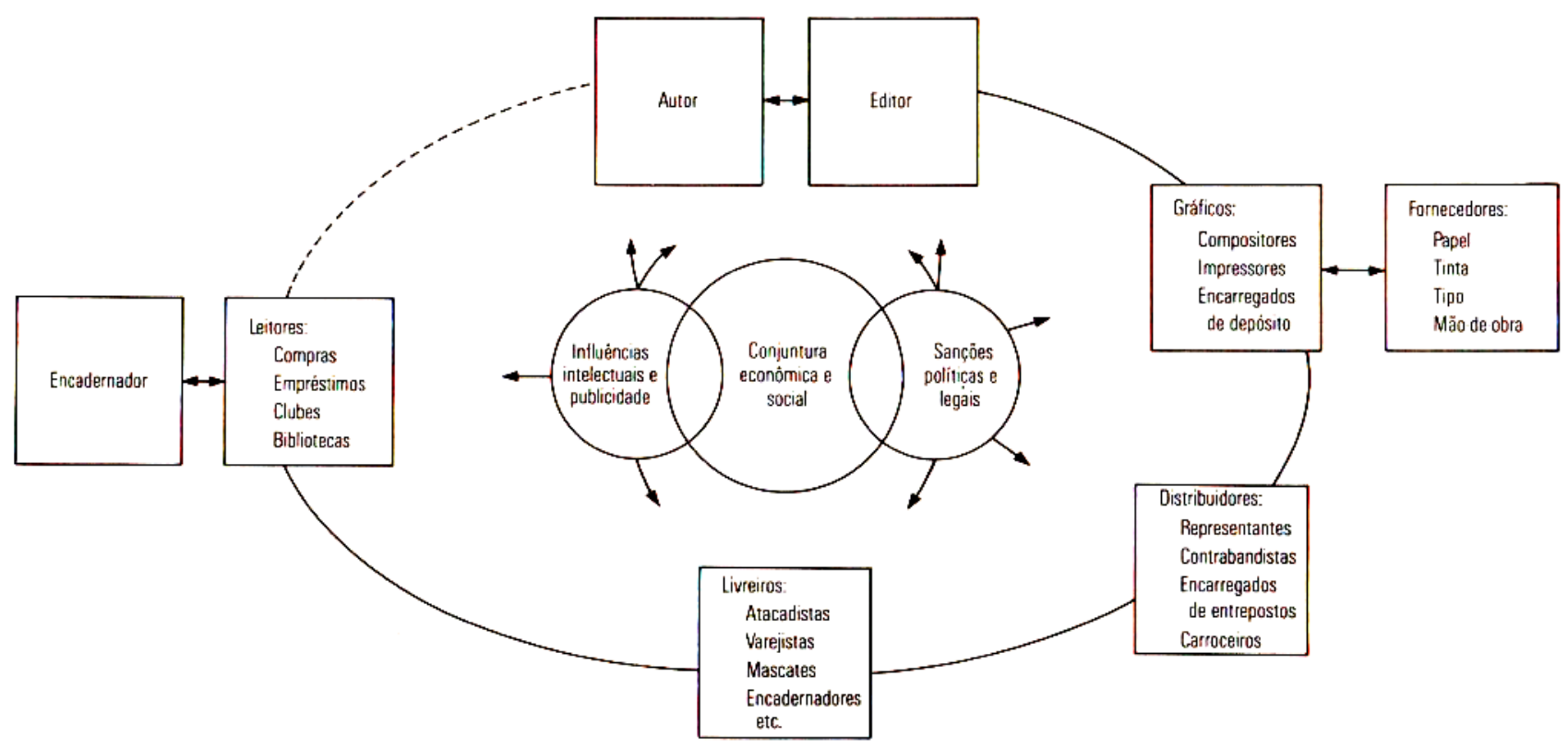

Figura 1 - Circuito das comunicações

Fonte: Darton, 2010, p 113.

$\mathrm{Na}$ representação proposta por Darnton (2010), as influências intelectuais e de publicidade, as conjunturas econômica e social e as sanções políticas e legais ocupam um papel central. Além de manterem relações entre si, elas podem exercer influências sobre os demais elementos - autor, editor, gráficos, fornecedores, distribuidores, leitores, dentre outros.

Para além das particularidades das considerações dos diversos autores, quando um periódico é tomado como fonte de pesquisa, constatamos que há uma convergência no que diz respeito à relevância de conhecer de modo mais aprofundado o documento em estudo, assim como as influências contextuais sobre o conteúdo em análise, que envolve não apenas as condições de produção, mas também as conjunturas intelectuais, políticas, econômicas, dentre outras, estabelecendo ainda o diálogo com outras fontes.

Levando em conta o exposto, procuramos aprofundar o conhecimento sobre a RE, traçando um breve histórico de sua circulação, percebendo como outras pesquisas a mobilizaram como fonte/objeto de investigação e destacando algumas das principais características das referências feitas à matemática e a seu ensino nos textos desse periódico. Para ampliar a compreensão dos significados associados às informações que circularam na Revista, entendemos ser necessário analisar todo o seu conteúdo e não apenas os artigos. Isso se justifica pelo fato de que a escrita é uma estrutura mista que se apoia em dois registros, verbal e gráfico, que, juntamente com as imagens (figura e suporte), definem os significados e intenções contidas em um texto (Belmiro, 2012, Almeida \& Belmiro, 2016). 
DOI: https://doi.org/10.20396/zet.v27i0.8653725

Com atenção às informações contextuais e às obtidas a partir de outras fontes, dedicamo-nos, a um estudo específico e "interno" da Revista do Ensino de Minas Gerais, o qual, conforme discutido por Catani (1996), tem como possibilidades

reconstruir, num momento dado, estágios de funcionamento e estruturação do campo educacional, movimentos de grupos de professores, disputas e atuações. Dito de outro modo, é possível partir do estudo de determinados periódicos educacionais e tomá-los como núcleos informativos, enquanto suas características explicitam modos de construir e divulgar o discurso legítimo sobre as questões de ensino e o conjunto das prescrições ou recomendações sobre formas ideais de realizar o trabalho docente (Catani, 1996, p.118).

Passamos, então, a apresentar um breve histórico da Revista do Ensino, elaborado principalmente a partir das informações expressas nas legislações que a regulamentaram ao longo de seu ciclo de vida.

\section{Trajetória histórica da Revista do Ensino de Minas Gerais}

A Revista do Ensino de Minas Gerais foi criada em 1892, a partir da Lei $\mathrm{n}^{\circ}$ 41, de 3 de agosto, com o objetivo de "promover o desenvolvimento da instrução e educação no Estado, reproduzir todos os atos oficiais a elas concernentes e vulgarizar os conhecimentos dos processos pedagógicos mais modernos e aperfeiçoados" (Lei 41 de 3 de agosto de 1892, 1893, p. 93).

De acordo com a Lei $\mathrm{n}^{\circ}$ 41, a Imprensa do Estado seria a responsável pela administração econômica da RE, a qual teria assinatura anual obrigatória para todos os professores e funcionários remunerados da instrução pública ${ }^{6}$. A mesma assinatura seria gratuita para todas as autoridades inspetoras do ensino no estado. Os exemplares da Revista seriam destinados, segundo o artigo 328, a cada uma das escolas públicas mineiras.

Os professores públicos eram, desde então, tidos como os colaboradores da RE, ficando a edição e revisão a cargo de algum docente do Ginásio Mineiro, da Escola Normal ou da Escola de Farmácia da Capital que tivesse sido eleito pelos seus pares nesses estabelecimentos. Além do conteúdo pedagógico e normativo, a RE também estaria aberta à publicação de defesas de professores e demais funcionários do estado processados ou condenados judicialmente. Seriam, ainda, veiculados recursos de candidatos que se julgassem injustamente reprovados ou prejudicados em concursos.

Segundo Biccas (2008), após a sua criação, em 1892, a Revista do Ensino teve apenas três exemplares publicados e foi desativada em seguida. Nesses exemplares, predominaram textos de caráter jurídico-administrativo, em detrimento de conteúdo pedagógico.

No governo de Melo Viana, a partir do Decreto $n^{\circ} 6.655$ de agosto de 1924, a Revista do Ensino foi reativada. No artigo 479 desse decreto, ficou determinado que a Diretoria da

\footnotetext{
${ }^{6} \mathrm{O} 2^{\mathrm{o}}$ parágrafo do artigo 325 afirmava que a assinatura anual da RE não deveria exceder $6 \$ 000$ para os professores e funcionários da instrução pública e $10 \$ 000$ para qualquer outra pessoa.
} 
DOI: https://doi.org/10.20396/zet.v27i0.8653725

Instrução se incumbiria da publicação mensal da Revista, a qual seria destinada a "orientar, estimular e informar os funcionários do ensino e os particulares interessados" (Decreto n. 6.655 - 19 agosto 1924,1924, p. 333).

No primeiro número da $\mathrm{RE}^{7}$ publicado após a reativação, em 8 de março de 1925, a Diretoria da Instrução assina, na primeira página, um artigo que traz algumas disposições do Decreto 6.655, reafirmando, assim, as diretrizes da Revista em sua nova fase:

A Revista do Ensino deverá constar:

$1^{\circ}$ de uma parte doutrinária destinada a:

a) dirigir o professorado público do Estado, harmonizando seus esforços;

b) pô-los ao corrente da evolução do ensino primário em todos seus aspectos;

c) publicar-lhes os trabalhos ou extratos destes, quando de evidente interesse didático;

$2^{\circ}$ de uma parte noticiosa destinada a publicar:

a) fatos e ocorrências locais, nacionais ou estrangeiras, que possam orientar os funcionários do ensino;

b) dados estatísticos relativos à instrução;

c) atos oficiais que interesse aos funcionários do ensino conhecer.

(Revista do Ensino, 1925(1), p.1)

Evidencia-se, na legislação, a proposta de que o conteúdo do periódico apresentasse características sobretudo pedagógicas, formativas e informativas para os professores e funcionários do ensino.

O Decreto 6.655 previa que na RE seriam publicados "pequenos trabalhos de interesse imediato, resumos de obras e de artigos extraídos de revistas congêneres, nacionais ou estrangeiras", trabalhos de colaboração dos funcionários do ensino (quando contivessem "matéria relevante"), além de resumos de relatórios dos inspetores técnicos regionais (Decreto n. 6.655 - 19 agosto 1924, 1924, p.333). Esses tipos de publicação de fato compuseram o conteúdo da RE, conforme veremos nas seções seguintes deste artigo.

Nada é dito no Decreto 6.655 sobre o envio dos exemplares da RE aos estabelecimentos escolares e sobre sua assinatura. Mas, no $\mathrm{n}^{\circ} 7$ do periódico, posto em circulação no dia 27 de setembro de 1925, no artigo intitulado "A Revista do Ensino nas Escolas e nos Grupos”, a Secretaria do Interior reforça a importância da leitura da Revista por todos os professores do estado e recomenda aos diretores de grupos escolares que "tanto nos grupos como nas escolas, não deixem faltar nunca os números da Revista, de tal modo que eles estejam sempre à mão para consulta ou leitura" (Revista do Ensino, 1925(7), p. 206). Além disso, esse mesmo artigo registrava um pedido para que os inspetores regionais, em suas visitas fiscalizadoras às escolas, tomassem o "cuidado primeiro" de verificar se a recomendação estava sendo cumprida. $\mathrm{O}$ mesmo artigo foi republicado no número 11 de 1926. Desse modo, nota-se que parecia haver um grande interesse por parte das lideranças político-educacionais no sentido de que a RE chegasse a todas as escolas de Minas, o que

\footnotetext{
${ }^{7}$ Ainda que no número 1 da Revista do Ensino (1925) haja a afirmação de que tal número inicia a publicação do periódico, conforme foi dito, Biccas (2008) refere-se a três números publicados antes, em 1892. Assim como nós, a autora não conseguiu localizar esses números.
} 
DOI: https://doi.org/10.20396/zet.v27i0.8653725

seria controlado por uma fiscalização, a cargo dos inspetores, da sua disponibilidade nos estabelecimentos de ensino.

Sabemos, no entanto, que a disponibilidade não era uma garantia de que o professor de fato usasse o periódico da forma como se esperava, como uma ferramenta de consulta e informação. Isso se confirma em um depoimento de uma professora diplomada pela Escola de Aperfeiçoamento ${ }^{8}$ que atuou por um semestre, no ano de 1931, em um grupo escolar do interior localizado no sul de Minas. O depoimento, publicado nos números 53-55 da RE, mostra as dificuldades inicialmente enfrentadas pelas lideranças do grupo escolar na motivação das professoras para aprofundarem os conhecimentos sobre a Reforma Francisco Campos (1927-1928), que estava sendo implementada em Minas Gerais, e sobre as propostas da Escola Nova em circulação. Nessa situação, a RE, que poderia servir como apoio, na visão da professora que escreve o depoimento, costumava sequer ser aberta pelas demais professoras:

Procurou a orientadora comunicar às educadoras do grupo um pouco de entusiasmo. Em palestras amistosas tentou despertar o interesse das colegas e fazê-las sentir a necessidade de ler livros novos, dos quais vários existiam na biblioteca do grupo, mas que lá estavam esquecidos, assim como as Revistas do Ensino que nem abertas eram (Revista do Ensino, 1931(53-55), p.116).

A partir do Decreto 7.877 de agosto de 1927, a Revista do Ensino passou a ser dirigida pelo Inspetor Geral da Instrução Pública, sendo a Inspetoria Geral da Instrução Pública a responsável pela edição mensal do periódico, mantendo-se praticamente as mesmas características do seu conteúdo afirmadas no Decreto 6.655.

No Decreto 7.877, a colaboração dos professores e funcionários públicos na RE foi tomada como um dos itens que ajudaria a denotar o "merecimento" desses profissionais, considerado quando ocorria um empate na concorrência para o provimento de cadeiras de docente nas escolas primárias. Isso poderia servir de incentivo aos professores para que contribuíssem com textos e relatos de experiências na Revista. O envio de colaborações foi ainda estimulado por um longo período na própria RE por meio dos concursos que premiavam os autores de textos selecionados.

Quando o cargo de Inspetor Geral da Instrução Pública foi extinto (Decreto 11.233 de 1934), criou-se o cargo específico de Diretor da Revista do Ensino e a publicação passou a ser um órgão técnico da Secretaria de Educação e Saúde Pública. O argumento para tal modificação era que a representatividade do periódico, em especial no momento em que a reforma do ensino atingia o máximo de desenvolvimento, demandava em sua direção "um homem de atividade e competência que se ocupasse exclusivamente dela" (Decreto n. 11.233 - 20 de fevereiro de 1934, 1934, p.45). Tal fato denota a importância atribuída a esse veículo

\footnotetext{
${ }^{8}$ A Escola de Aperfeiçoamento, inaugurada em março de 1929 como um desdobramento da Reforma Francisco Campos (1927-1928), tinha como objetivo principal preparar as docentes mineiras para colocarem em prática, em sua atuação nas escolas, os princípios da Escola Nova.
} 
DOI: https://doi.org/10.20396/zet.v27i0.8653725

de comunicação para a difusão das ideias e preceitos associados às reformas, assim como a alta expectativa quanto ao seu papel formativo para os professores e funcionários do ensino.

A Revista do Ensino manteve suas publicações até 1940, quando sua circulação foi interrompida devido à Segunda Guerra Mundial. Após isso, o periódico voltou a circular novamente em 1946.

No Decreto 6.002 de novembro de 1960, que definiu o regulamento da Secretaria de Educação ${ }^{9}$ mineira, as responsabilidades desse órgão em relação à RE foram mais uma vez reafirmadas: garantir a publicação mensal do periódico; manter uma seção da Revista para o tratamento de questões administrativas, legislativas e regulamentar e solicitar aos seus diversos departamentos colaborações na forma de textos. A partir de 1963, a Lei 2.829 dispôs que a publicação da RE seria feita por intermédio do Departamento de Educação (integrante da Secretaria de Educação).

A Revista do Ensino foi extinta em 1971, no governo de Rondon Pacheco.

Vê-se, portanto, que, ao longo de todo o seu ciclo de vida, diversas iniciativas foram empreendidas e legalmente oficializadas para garantir a circulação e a distribuição do periódico, a colaboração e o acesso dos professores, além do perfil formativo e informativo do seu conteúdo. Levando em conta tais características, Biccas (2008) avalia a Revista do Ensino de Minas Gerais como o periódico oficial "mais representativo da história da educação mineira, não só pelo seu longo ciclo de vida, mas pelo papel significativo no processo de formação de professores e conformação do campo educacional mineiro" (p.15).

Tendo em vista essa representatividade da Revista e o seu potencial para a análise de temas associados à educação em Minas Gerais e aos seus desdobramentos no campo das disciplinas escolares (Biccas, 2006, p.96), diversos trabalhos tomaram esse impresso como objeto e/ou fonte de pesquisa, alguns dos quais comentamos na seção seguinte.

\section{Estudos anteriores sobre a Revista do Ensino}

Com o propósito de localizar estudos de mestrado ou doutorado que utilizaram a Revista do Ensino de Minas Gerais como fonte e/ou objeto de investigação, fizemos uma consulta ao Catálogo de Teses e Dissertações da Capes e ao acervo da Biblioteca Digital Brasileira de Teses e Dissertações - BDTD. Nas duas plataformas ${ }^{10}$, usamos o termo de busca "Revista do Ensino" e, analisando o conteúdo dos resultados listados, filtramos os que se referiam à Revista do Ensino de Minas Gerais. Constatamos, assim, a existência de 20 dissertações e 12 teses que tomam esse impresso como fonte de pesquisa ou objeto de investigação. Percebe-se que esses trabalhos integram uma produção bastante recente,

\footnotetext{
${ }^{9}$ Com o Decreto-lei 1724 de 1946, a Secretaria de Educação e Saúde Pública passou a denominar-se Secretaria de Educação.

10 As plataformas foram acessadas pelos sites http://catalogodeteses.capes.gov.br/catalogo-teses/ e http://bdtd.ibict.br/vufind/ no perídio de 20 a 29 de abril de 2018.
} 
DOI: https://doi.org/10.20396/zet.v27i0.8653725

desenvolvida principalmente a partir do ano 2000. A única exceção é o estudo de Borges (1993).

Nesse universo de 32 trabalhos, quatro desenvolveram análises sobre aspectos da matemática na escola primária ou normal mineira tomando a RE como fonte: Barros (2015), Caputo (2017), Mendonça (2016) e Rezende (2016).

Barros (2015) estudou como a geometria era ensinada na formação de professores primários em Minas Gerais entre as décadas de 1890 e 1940, usando como fonte cadernos de ex-alunas da Escola de Aperfeiçoamento e exemplares da RE que circularam no período. Caputo (2017) teve por objetivo investigar as características do desenho como saber ensinado na escola primária em Minas Gerais entre 1925 e 1932 e tomou por base artigos que tratam do assunto publicados na RE nesse período. Mendonça (2016) pesquisou a presença da geometria no ensino primário de Minas Gerais entre 1960 e 1970, procurando perceber traços das ideias associadas ao Movimento da Matemática Moderna (MMM) em circulação no referido período. Rezende (2016), por fim, investigou as apropriações dos princípios da psicologia de Edward Lee Thorndike para o ensino de saberes elementares matemáticos por autores de manuais pedagógicos e por artigos publicados em revistas pedagógicas brasileiras que circularam entre 1920 e 1960.

A pesquisa que desenvolvemos se aproxima das anteriormente comentadas na medida em que investiga as referências feitas à matemática e a seu ensino em textos da Revista do Ensino, fazendo desse periódico a principal fonte principal de investigação. Porém, nosso trabalho focaliza todos os discursos sobre essa temática veiculados nas páginas da RE, diferenciando-se dos estudos mencionados anteriormente, que incidem sobre temas específicos. A seguir, apresentamos procedimentos metodológicos que utilizamos e alguns resultados da pesquisa.

\section{Panorama geral das referências à matemática ou a seu ensino na Revista do Ensino}

Durante o ciclo de vida da Revista do Ensino de Minas Gerais (1925 a 1971), foram postos em circulação 239 números do periódico, sendo 175 na primeira fase (1925 a 1940) e 64 na segunda fase (1946 a 1971). Esses números se encontram organizados em 172 volumes, ou seja, existem volumes que trazem mais de um número do periódico.

Com o propósito de fazer o levantamento dos textos da RE que fazem referência à matemática ou a seu ensino, analisamos os 236 números (169 volumes) da RE que estavam disponíveis, em 6 de maio de 2018, no site do Arquivo Público Mineiro (http://www.siaapm.cultura.mg.gov.br/), na plataforma Hélio Gravatá ${ }^{11}$.

Ao examinarmos cada uma das páginas dos 169 volumes da RE comentados, identificamos, ao todo, 346 textos (verbais e/ou imagens) nos quais encontramos referências à

\footnotetext{
${ }^{11}$ Na Plataforma Hélio Gravatá não estavam disponíveis os números 219, de 1964; 230, de 1967 e 239, de 1971, que por esse motivo não foram investigados.
} 
DOI: https://doi.org/10.20396/zet.v27i0.8653725

matemática, como campo de conhecimento, como conteúdo escolar do ensino primário ou do ensino normal (associado à diferentes matérias dos programas oficiais daquela época, como, por exemplo, Aritmética, Geometria, Álgebra, Metodologia da Aritmética) ou, ainda, como saber a ser ensinado, para o qual se apontavam instruções e orientações próprias.

Sempre que alguma menção à matemática desse tipo foi encontrada, realizamos o registro do número do periódico, do título associado ao artigo/ seção/ anúncio/ imagem, das páginas e do nome do autor, quando esse é informado.

No gráfico a seguir, está a distribuição quantitativa das referências encontradas em cada ano de circulação da Revista do Ensino. Os anos marcados com asterisco (*) são aqueles em que nem todos os números da Revista estavam disponíveis para consulta no acervo do Arquivo Público Mineiro.

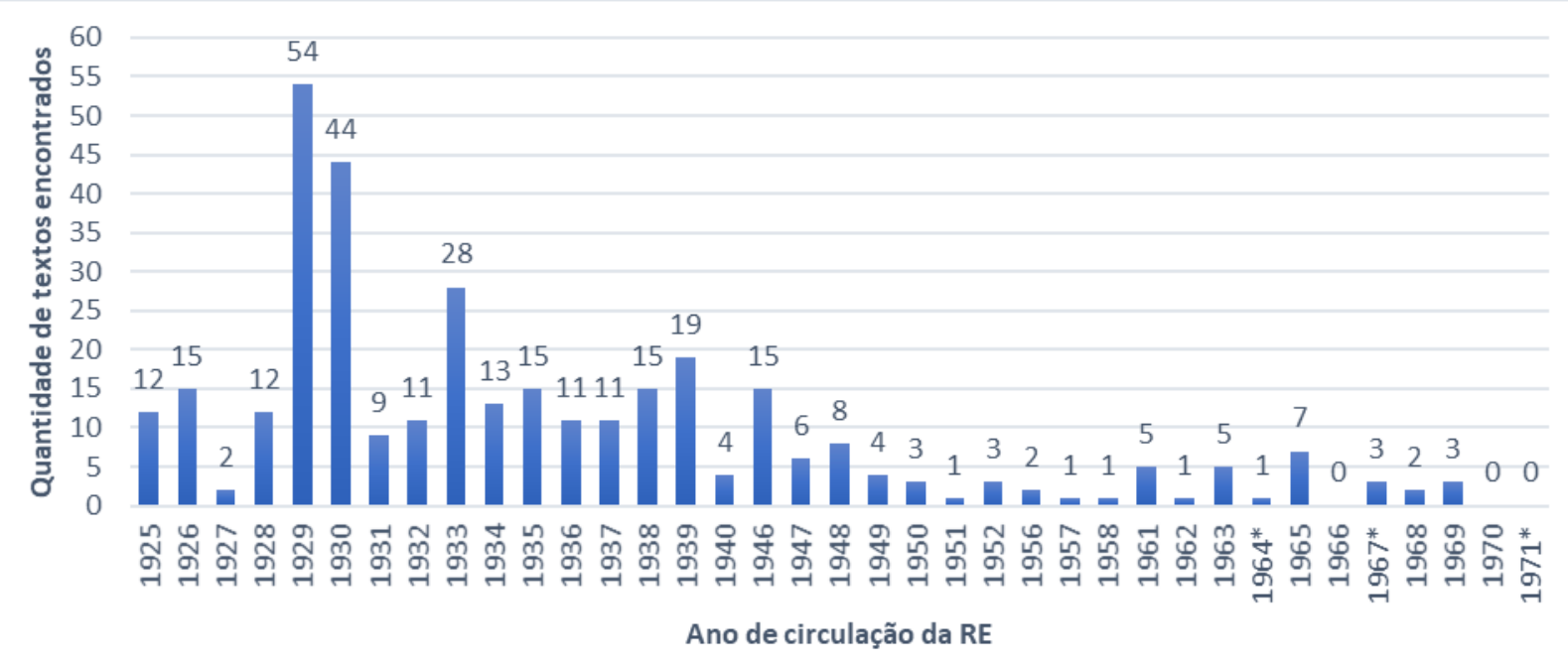

Gráfico 1 - Distribuição quantitativa de textos com referências à matemática ou a seu ensino na RE ao longo de seu ciclo de vida - 1925 a 1971

Nota-se, pelo Gráfico 1, que a quantidade de textos com referências à matemática e a seu ensino é expressivamente maior na primeira fase da Revista do Ensino (1925 a 1940) em comparação com a sua segunda fase, após 1946. Isso, em parte, se explica pelo fato de que a quantidade de números publicados após 1946 é também significativamente menor (64 dos 239 números).

Os anos de 1929 e 1930 são aqueles em que um maior número de textos com referências de nosso interesse foi encontrado. Supomos que isso esteja associado à grande preocupação existente, nesse período, em levar ao conhecimento dos leitores informações sobre as reformas que se processavam no campo educativo mineiro (Reforma Francisco Campos em 1927-1928), fazendo circular orientações aos professores quanto às propostas advindas dos novos programas do ensino primário e normal aprovados em 1927 e 1928, respectivamente. Também se tratava de um período de grande efervescência pedagógica, em que crescia a circulação de ideias associadas ao movimento da Escola Nova, o que se desdobrava em um maior número de publicações na RE. 
Nem todos os textos do nosso corpus trazem informações sobre autoria. Notamos que no período de 1925 a 1971, há um total de 85 textos sem autoria informada ou com autoria indicada por pseudônimos ou siglas que não possibilitaram a identificação, o que corresponde a cerca de $24 \%$ do total. Consideramos que uma boa parte desses textos de autoria não identificada possa ser de responsabilidade da própria redação da Revista do Ensino, já que muitos se assemelham bastante em conteúdo e formato aos que são indicados como publicações da redação da Revista. No entanto, acreditamos que em alguns deles a não identificação da autoria esteja relacionada à intenção de garantir o anonimato das ideias comunicadas.

Dezenove textos de nosso levantamento foram escritos em conjunto por dois ou mais autores. Chamamos de coautores as pessoas que tiveram textos publicados em colaboração/ parceria com outras pessoas (ao todo 40 pessoas). Ao todo, identificamos 194 autores/ coautores dos textos investigados.

Constatamos que 144 desses autores/coautores (cerca de 74\%) publicaram apenas um texto com referências à matemática ou a seu ensino na RE. Somente 10 autores/coautores, juntamente com a Redação da RE, assinaram mais de três textos que fazem referência às temáticas de interesse de nossa pesquisa. Essa grande quantidade de autores/coautores com uma única publicação tanto pode estar ligada ao perfil do periódico, que tinha como objetivo receber e publicar contribuições dos professores e funcionários das mais diversas regiões do estado, como também pode indicar que apenas um pequeno número de pessoas detinha um discurso representativo, ou participava de redes de sociabilidade com poder na Revista, o que resultou em uma maior quantidade de artigos publicados.

De fato, temos entre os autores/coautores com um número grande de publicações personalidades de destaque no campo educacional e político mineiro. Dentre elas, podemos citar Helena Antipoff, professora do Instituto J. J. Rousseau de Genebra e da Escola de Aperfeiçoamento de Belo Horizonte, com 8 textos; Maurício Murgel, vice-diretor da Escola Normal Modelo e diretor da Secretaria de Educação, com 7 textos; e Mário Casasanta, participante de destaque na implementação da Reforma Francisco Campos, inspetor da Instrução Pública e diretor da Imprensa Oficial, com 7 textos.

O número de autores/coautores que publicaram textos com referências à matemática ou a seu ensino na segunda fase da RE é bem pequeno perto do total: apenas 38. Além disso, somente seis deles tiveram textos veiculados nas duas fases do periódico: Aimoré Dutra, Editora/ Cia Melhoramentos, Irene Lustosa, Marieta Araújo, Maria da Glória de Barros e Zilah Frota.

A identificação do(s) autor(es)/coautor(es) - cargo ocupado, local de atuação profissional, dentre outros dados - vinha, em alguns casos, registrada abaixo dos seus nomes ou no corpo do texto da Revista. Conseguimos informações sobre a trajetória profissional/acadêmica/política de 110 dos autores/coautores que assinaram textos com as referências de nosso interesse até o ano de 1940. 
DOI: https://doi.org/10.20396/zet.v27i0.8653725

Notamos que os autores/coautores dos textos que fazem referência à matemática ou a seu ensino na RE até 1940 são predominantemente professores ou diretores de escolas primárias, além de assistentes técnicos do ensino. Convém observar que é expressiva a autoria/coautoria de professores e diretores de escolas primárias do interior, o que sinaliza o alcance da RE quanto às diferentes localidades do estado de Minas Gerais. Outros aspectos que chamam a atenção são o reduzido número de autores e coautores que atuavam no ensino normal, a presença de autores/ coautores estrangeiros, além de personalidades no campo da política ou educação nacional e mundial, dentre as quais se encontram alguns grandes nomes do movimento escolanovista, como Adolphe Ferrière, John Dewey e Anísio Teixeira.

\section{Tipos de textos que contemplam a matemática ou seu ensino na RE}

A leitura dos textos que contemplam a matemática ou seu ensino até o ano de 1940 nos levou à seguinte categorização quanto a seu formato:

1) artigo de opinião;

2) trabalho premiado pela Revista do Ensino;

3) extrato de monografia;

4) imagem $^{12}$;

5) resenha/síntese/análise de livros;

6) legislação/normativa/comunicado da gestão do Estado;

7) notícia;

8) plano de lição/excursão/projeto;

9) propaganda;

10) relato de experiência, observação, pesquisa ou estudo;

11) tex to já publicado em outros veículos;

12) tradução;

13) transcrição de palestra/conferência;

14) outro.

A última categoria (outro) foi associada aos textos que não correspondem adequadamente a nenhum dos treze tipos anteriores. Certos textos encontram-se classificados em mais de um dos tipos acima, devido às características do seu conteúdo.

\footnotetext{
${ }^{12}$ Essa categoria foi associada apenas aos textos que se compunham exclusivamente de uma imagem, ou uma imagem com alguma sentença verbal muito curta (como uma legenda), em que se percebe alusão à matemática ou a seu ensino. Temos, ao todo, mais 17 textos que são ilustrados, no entanto são predominantemente verbais. Os outros 254 textos que completam o nosso corpus no período de 1925 a 1940 são apenas verbais.
} 
DOI: https://doi.org/10.20396/zet.v27i0.8653725

A quantificação dos textos nessas 14 categorias encontra-se sistematizada no Gráfico 2.

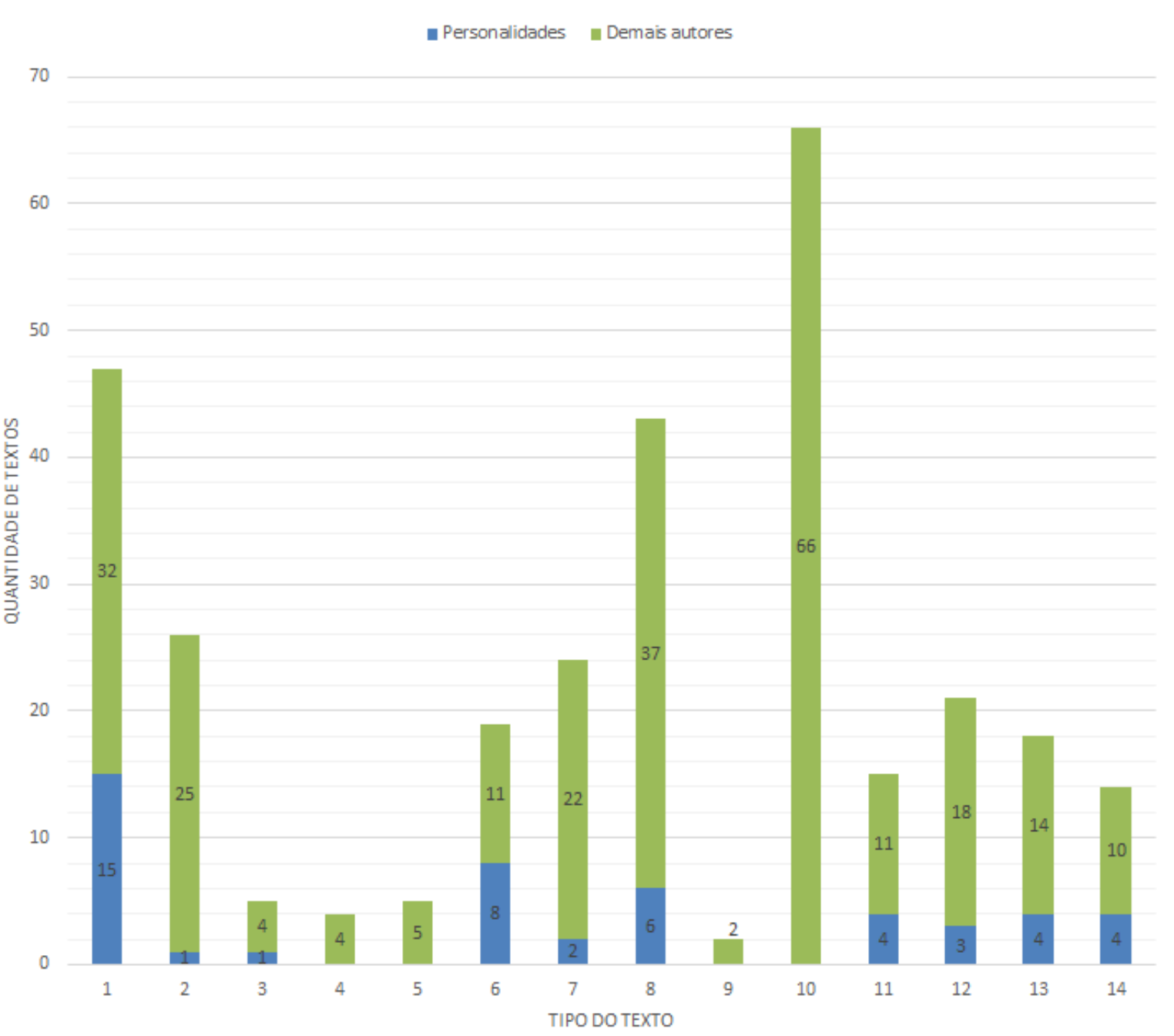

Gráfico 2 - Tipos de textos que contemplam a matemática ou seu ensino na RE até 1940

O Gráfico 2 evidencia que os tipos de textos que contemplam a matemática ou seu ensino na RE até 1940 são predominantemente relatos de experiência, observação, pesquisa ou estudo (categoria 10); artigos de opinião (categoria 1) e planos de lição/excursão ou projeto (categoria 8 ).

No gráfico, para cada categoria, o azul indica a quantidade de textos cujos autores/coautores são personalidades do campo político educacional e o verde mostra a quantidade correspondente aos demais autores e coautores. Nota-se que, para alguns tipos de textos, é bem expressivo o número de autores e coautores personalidades do cenário político ou acadêmico. Isso acontece com os artigos de opinião (categoria 1), os que se concernem a uma legislação ou normativa ou comunicado da gestão do Estado (categoria 6) e os textos já publicados em outros veículos (categoria 11). Nos relatos de experiência, observação, pesquisa ou estudo (categoria 10), por outro lado, não identificamos autores ou coautores que foram personalidades de destaque no campo educacional e político mineiro. Interpretamos 
DOI: https://doi.org/10.20396/zet.v27i0.8653725

que a presença mais marcante desses autores nas categorias 1, 6 e 11 e a pequena participação em outras relacionadas ao relato da prática tem vinculação às funções ocupadas por eles ou elas, as quais estavam diretamente associadas às questões administrativas do ensino, assim como à circulação de ideias e preceitos gerais (a exemplo das orientações para as reformas educacionais).

Categorias temáticas dos textos que contemplam a matemática ou seu ensino na RE até 1940

Também propusemos uma categorização de cada um dos textos de nosso corpus publicados até 1940 de acordo com as temáticas focalizadas nas referências feitas à matemática e a seu ensino. $\mathrm{O}$ exame dos textos conduziu à fixação das seguintes categorias:

(i) a matemática em currículos e programas de ensino;

(ii) abordagem da matemática nas escolas após as reformas de 1927;

(iii) concepções, visões e valores relacionados à matemática e/ou seu ensino;

(iv) ensino da matemática em outros países ou outros países como modelo para o ensino de matemática;

(v) formação para professores e/ou profissionais da educação envolvendo a matemática e/ou seu ensino;

(vi) orientações, sugestões ou exemplos para abordagem de conteúdos matemáticos pelos professores;

(vii) participação da matemática em projetos, excursões ou centros de interesse;

(viii) recursos e materiais a serem usados no ensino de matemática ou na formação do professor;

(ix) testes, provas, avaliações de concurso ou de desempenho de alunos envolvendo matemática;

(x) outros.

Textos que não se inserem em qualquer das 9 categorias temáticas anteriores foram alocados na $10^{\text {a }}$ categoria temática - outros. Alguns textos foram associados a mais de uma categoria por envolver mais de uma temática.

No Gráfico 3, a seguir, estão sintetizados os números de textos correspondentes a essa classificação. 
DOI: https://doi.org/10.20396/zet.v27i0.8653725

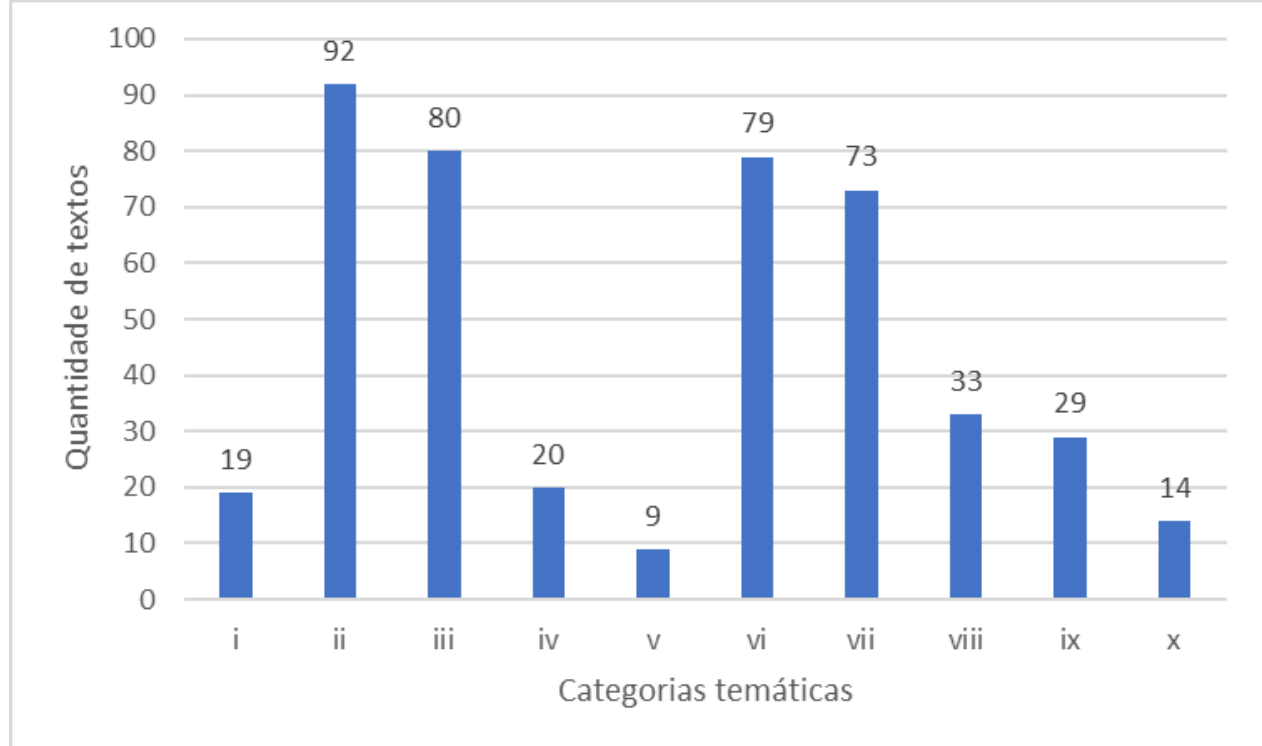

Gráfico 3- Categorias temáticas dos textos que fazem referências à matemática ou a seu ensino publicados na RE até 1940

As categorias temáticas (ii) (abordagem da matemática nas escolas após as reformas de 1927), (iii) (concepções, visões e valores relacionados à matemática e/ou seu ensino, (vi) (orientações, sugestões ou exemplos para abordagem de conteúdos matemáticos pelos professores) e (vii) (participação da matemática em projetos, excursões ou centros de interesse) se destacam como as representadas em maior quantidade no corpus de pesquisa.

Entendemos que a predominância de textos com tais temáticas se relaciona tanto aos tipos de textos mais frequentemente publicados na RE, conforme comentamos no tópico anterior, como também à proposta de conteúdo definida para a RE desde a sua ativação em 1925, que estava relacionada à divulgação de experiências e propostas de ensino consideradas bem sucedidas e coerentes com as diretrizes pedagógicas e curriculares traçadas no plano oficial através dos regulamentos e programas de ensino.

Outro ponto a ser notado é que, ainda que os projetos, excursões e centros de interesse fizessem parte de publicações da RE anteriores à Reforma Francisco Campos (1927-1928), essas temáticas foram mais frequentemente focalizadas a partir das orientações presentes nas legislações que vigoraram com a referida Reforma. Com isso, um bom número dos trabalhos associados à categoria temática (vii) também foi vinculado à categoria temática (ii), o que favoreceu o seu aparecimento conjunto entre as categorias mais recorrentes.

\section{Considerações finais}

Neste texto, discutimos aspectos teórico-metodológicos relacionados ao uso de periódicos educacionais como fonte de pesquisa e abordamos um impresso específico, a Revista do Ensino de Minas Gerais, como material documental relevante para a investigação da história da educação mineira, de modo geral, e da história da educação matemática, de modo particular. 
DOI: https://doi.org/10.20396/zet.v27i0.8653725

Debruçando-nos sobre um universo de 346 textos assinalados por nossa leitura como portadores de qualquer tipo de referência à matemática ou a seu ensino, publicados nos 236 números do periódico a que tivemos acesso, procedemos a análises que levaram a categorizações e quantificações do material em relação a suas características de forma e conteúdo. Esses procedimentos nos possibilitarão avançar em nossa investigação, voltada para os modos como a matemática e seu ensino foram representados na Revista do Ensino de Minas Gerais no período transcorrido entre 1925 e 1940.

Para além da visão panorâmica aqui apresentada, procedemos, no momento em que escrevemos este artigo, a um estudo mais fundamentado e aprofundado dos aspectos contextuais e do próprio conteúdo dos textos de nosso corpus de pesquisa. Esperamos, em breve, poder divulgar outros resultados e desdobramentos dessa investigação.

\section{Referências}

Almeida, T. A. \& Belmiro, C. A. (2016). Literatura infantil e multimodalidade: o papel dos paratextos no livro ilustrado. Pesquisas em discurso pedagógico, (1), 1-17.

Barros, S. de C. (2015). O ensino de geometria na formação de professores primários em Minas Gerais entre as décadas de 1890 e 1940. 2015. Dissertação de mestrado em Educação Matemática. Juiz de Fora: Universidade Federal de Juiz de Fora.

Bastos, M. H. C. A. (2007). A imprensa de educação e de ensino: repertórios analíticos. O exemplo da França. [Resenha do livro La presse d'éducation et d'enseignement. 19411990. Répertoire analytique, de P. Caspard-Karydis]. Revista Brasileira de Educação, 12(34), 166-168.

Belmiro, C. A. (2012). Entre modos de ver e modos de ler, o dizer. Educação em Revista, Belo Horizonte, 28(4), 105-131.

Biccas, M. de S (2006). Impresso pedagógico como objeto e fonte para a História da Educação em Minas Gerais: Revista do Ensino (1925-1940). In C. Morais, E. A. Portes, \& M. A. Arruda. História da Educação: Ensino e pesquisa. Belo Horizonte: Autêntica.

Biccas, M. de S (2008). O impresso como estratégia de formação: Revista do Ensino de Minas Gerais (1925-1940). Belo Horizonte: Argvmentvm.

Borges, V. L. A. (1993). A ideologia do caráter nacional da educação em Minas: Revista do Ensino (1925-1929). Dissertação de Mestrado em Educação. Campinas: Universidade Estadual de Campinas, Faculdade de Educação.

Brito, A. J., \& Miorim, M. A. (2012). Histórias de periódicos e da Educação Matemática no Brasil: Possíveis relações. Educação Matemática e Pesquisa, São Paulo, 14(3), 439464.

Búrigo, E. Z. (2016). Problemas aritméticos em livros, revistas e programas: um exercício de cruzamento de fontes. Histemat, 2(1), 190-204.

Caputo, D. R. (2017). O saber desenho no ensino primário a partir das Revistas do Ensino de Minas Gerais (1925 A 1932): sua concepção e as profissionalidades. Dissertação de Mestrado Profissional em Educação Matemática. Juiz de Fora: Universidade Federal de Juiz de Fora. 
DOI: https://doi.org/10.20396/zet.v27i0.8653725

Carvalho, M. M. C. de (2001). A Escola Nova e o impresso: um estudo sobre as estratégias editoriais de difusão do escolanovismo no Brasil. In: L. M. de Faria Filho, (Orgs.). Modos de ler/Formas de escrever: estudos de história da leitura e da escrita no Brasil. Belo Horizonte: Autêntica.

Catani, D. B. A (1996). A imprensa periódica educacional: as revistas de ensino e o estudo do campo educacional. Educação e Filosofia. 10(20), 115-130.

Chartier, R. (1990). A História Cultural: entre práticas e representações. Lisboa: Difel.

Cruz, H. de F., \& Peixoto, M. do R. da C. (2007). Na oficina do historiador: conversas sobre história e imprensa. Projeto História. 35, 255-272.

Darnton, R. (2010). O beijo de Lamourette: mídia, cultura e revolução. São Paulo: Companhia das Letras.

Decreto n. 6.655 - 19 agosto 1924. (1924). Aprova o Regulamento do Ensino Primário. Colleção das Leis e Decretos do Estado de Minas Gerais. Belo Horizonte: Imprensa Oficial.

Decreto n. 7.877 - 30 de agosto de 1927. (1928). Aprova o Regulamento do Ensino Primário. Colleção das Leis e Decretos do Estado de Minas Gerais. Belo Horizonte: Imprensa Oficial, vol.II.

Decreto n. 11.233 - 20 de fevereiro de 1934. (1934). Extingue o cargo de inspector geral da instrução e diretor da "Revista do Ensino", e cria os cargos de auxiliar técnico do Secretário da Educação e diretor da "Revista do Ensino. Colleção das Leis e Decretos de 1934. Belo Horizonte: Imprensa Oficial.

Decreto-lei n. 1.724 - 24 de abril de 1946. (1946). Dá autonomia e nova denominação à Diretoria de Saúde Pública. Belo Horizonte: Minas Gerais.

Decreto n. 6.002 - 29 de nov. de 1960. (1960). Aprova o regulamento da Secretaria de Educação. Belo Horizonte: Diário do Executivo.

Faria Filho, L. M. (1997). A história da educação e os desafios das novas fontes: reflexões sobre uma trajetória de pesquisa. Revista História da Educação, 1(2), 111-125.

Farias, K. S. C. S. (2014). Jornais, revistas e periódicos - corpus forte em histórias do ensino de matemática: isso nos dizem as pesquisas do HIFEM. In A. de J. Brito, K. S. C. Farias S. \& M. Â. Miorim (Orgs.). Pesquisas históricas em jornais e revistas: produções do HIFEM. São Paulo: Editora Livraria da Física.

Fernandes, F. S. \& Kuhlmann Júnior, M. (2012). Análise de periódicos na história da educação: princípios e procedimentos. Cadernos de Pesquisa, 42, 562-585.

Lei 41 de 3 de agosto de 1892. (1893). Da nova organização à instrução pública do Estado de Minas. Colleção das Leis e Decretos do Estado de Minas Gerais em 1892. Ouro Preto: Imprensa Oficial de Minas Gerais.

Lei n. 2.829 - 08 de fev. de 1963. (1963). Dispõe sobre a "Revista do Ensino", órgão da Secretaria da Educação. Belo Horizonte: Minas Gerais Diário do Executivo.

Luca, T. R. de. (2005). História dos, nos e por meio dos periódicos. In C. B. Pinsky, (Org.). Fontes Históricas. São Paulo: Contexto.

Mendonça, T. N. (2016). Que geometria ensinar às crianças em tempos de matemática moderna? Referências e práticas de uma professora da cidade de Juiz de Fora. 
DOI: https://doi.org/10.20396/zet.v27i0.8653725

Dissertação de Mestrado Profissional em Educação Matemática. Juiz de Fora: Universidade Federal de Juiz de Fora.

Rezende, A. M. S. de. (2016). Apropriações de teorias de Edward Lee Thorndike para o ensino dos saberes elementares matemáticos em revistas pedagógicas brasileiras (19201960). Dissertação de Mestrado em Ensino de Ciências e Matemática. São Cristóvão: Fundação Universidade Federal de Sergipe.

Revista do Ensino. (1925). Belo Horizonte: Diretoria da Instrução Pública do Estado de Minas Gerais, $1(1)$.

Revista do Ensino. (1925b). Belo Horizonte: Diretoria da Instrução Pública do Estado de Minas Gerais, 1(7).

Revista do Ensino. (1931). Belo Horizonte: Diretoria Inspetoria Geral da Instrução do Estado de Minas Gerais, 7(53-55).

Rios, D. F. \& Fischer, M. C. B. (2016) Especialmente dedicada aos futuros espaçonautas: discursos modernizadores nos artigos da Campanha de Matemática da Revista do Ensino/RS. Revista Diálogo Educacional, Curitiba, 16(49), 589-610.

Sousa, C. P. de \& Catani, D. B. (1994). A imprensa periódica educacional e as fontes para a História da Cultura Escolar Brasileira. Revista do Instituto de Estudos Brasileiros, São Paulo, (37), 177-183.

Toledo, C. de A. A. de \& Skalinski Junior, O. (2012). A imprensa periódica como fonte para a História da Educação: Teoria e Método. Revista HISTEDBR On-line, Campinas, (48), 255-268. 